\title{
Product-Related Environmental Regulation, Innovation, and
}

\section{Competitiveness: Empirical Evidence from Malaysian and}

\author{
Vietnamese Firms
}

November 10, 2017

\author{
Qizhong YANG ${ }^{\dagger}$ \\ PhD Candidate, The Graduate School of Economics, Osaka University \\ Tsunehiro OTSUKI \\ Professor, Osaka School of International Public Policy, Osaka University
}

\begin{abstract}
【Keywords】RoHS, REACH, Innovation, Productivity, Porter Hypothesis
【JEL Classification】F18, O31, Q55, Q56

【Abstract】This study examined the impact of two PRERs released by the EU-RoHS and REACH - on Malaysian and Vietnamese firms' compliance. The analysis considers productivity as a realization of innovations and examines the R\&D enhancement effect of PRERs. The effect of PRERs on productivity is also broken down into direct and indirect effects through $R \& D$ enhancement. The result shows that the response to REACH can create incentives to advance $R \& D$, and productivity can increase through both direct and indirect channels. No relationship between the response to RoHS and R\&D expenditure is found. Further analysis shows that firms comply with RoHS and REACH in different ways, but just the ability to continue exporting to the EU motivates compliance.
\end{abstract}

\footnotetext{
${ }^{\dagger}$ Corresponding author. Graduate School of Economics, Osaka University, Address: 1-7, Machikaneyama, Toyonaka, Osaka, 560-0043, JAPAN.

E-mail: u759184c@ecs.osaka-u.ac.jp
} 


\section{Introduction}

In the past decade, developed countries have increasingly adopted product-related environmental regulations (PRERs), led by the EU, predominantly for protection of the environment and consumer health. Well-known PRERs adopted by the EU include the End of Life Vehicles Directive (ELV); Waste Electrical and Electronic Equipment Directive (WEEE); Restriction of Hazardous Substances Directive (RoHS); and Registration, Evaluation, Authorization and Restriction of Chemicals Regulation $(\mathrm{REACH})$. As they regulate hazardous and chemical substances, these PRERs require non-inclusion or reduction of controlled substances at the manufacturing stage to prevent harmful pollution.

PRERs help firms reduce the environmental burden at each production stage since final products launched in the EU must meet the stipulated standards; producers exporting to the EU must review their product's life cycle-design, procurement, manufacture, transport, consumption, and disposal. Thus, such regulations may harm firms' competitiveness by imposing higher production costs as previous studies pointed out (e.g. Jorgenson and Wilcoxen, 1990). However, these processes may induce firms to make continuous efforts toward innovation for better product functionality for environmental or consumer safety. Porter and van der Linde (1995) claimed that well-designed environmental regulations promote technological innovation that improves firms' competitiveness by increasing efficiency and encouraging innovation. This is widely recognized as the Porter Hypothesis. This underlying mechanism motivates us to examine whether PRERs such as RoHS and REACH can trigger technological innovation, although these regulations are imbedded in products as attributes to be satisfied and are enforced across borders. However, firms can evade 
compliance to these regulations by diverting the export destination. Furthermore, although they comply with the regulations, they might not have incentive to go beyond meeting the minimum requirement, resulting in inadequate effort toward innovation to attain higher level of environmental or consumer safety.

The Porter Hypothesis claims that stringent environmental regulations can achieve a win-win situation, wherein an economy can simultaneously attain the goals of cleaner environment and competitiveness. In this hypothesis, technological change is a predominant factor for solving long-term environmental problems and serves as a prerequisite. Although the Porter Hypothesis has attracted widespread attention, Palmer et al. (1995) and others criticized it for being incompatible with the assumption that firms are profit maximizing (Ambec et al., 2013). Furthermore, industries in developed countries may seek looser environmental legislation in developing countries (“industrial flight hypothesis"), while developing countries may impose weaker environmental standards to maintain competitiveness and attract potential investors ("pollution haven hypothesis"; Chatzistamoulou et al., 2017). Moreover, the Porter Hypothesis's applicability in terms of PRERs depends on the regulations' characteristics. The innovation-promoting effect of environmental regulations is more explicit than that of regulations aimed at consumer health protection. Thus, the Porter Hypothesis is more likely to hold for PRERs with greater focus on environment protection (e.g. ELV and WEEE) than those focusing equally on environmental and consumer protection (e.g. RoHS and REACH).

This study examines the impact of two PRERs adopted by the EU-RoHS and REACH—on Malaysian and Vietnamese firms' performance. As these PRERs address potential impacts on both environment and consumer health, their causal effect on 
firms' performance has many unknown aspects. The analysis considers productivity as a realization of innovation and examines the research and development (R\&D) enhancement effect of PRERs, focusing on both direct and indirect channels; the latter implies that PRERs affect productivity through R\&D enhancement. The analysis employs firm-level survey datasets for Vietnam and Malaysia collected by the Institute of Developing Economies and Japan External Trade Organization (IDE-JETRO). This study specifically focuses on both RoHS and REACH because they cover a wider range of industries and have less predictable impact on firms' innovation than other PRERs, particularly those focusing on the environment.

The result shows that REACH can trigger firms' R\&D, which also raises productivity. However, the relationship between the response to RoHS and R\&D expenditure is not confirmed. These mixed results should be viewed as evidence of PRERs' innovation-promoting effect contingent on their characteristics. Further estimation investigates the causal effect between PRERs and changes in inputs and product prices by exploring the evolution of prices. The results show that to comply with RoHS, firms choose to change the input instead of innovating. Finally, no significant effect was observed between compliance with the two PRERs, and change in product prices, indicating that neither RoHS nor REACH would lead to upgrades in product quality.

This study contributes to the literature from the following perspectives. First, this study focuses on RoHS and REACH, which have not been considered by previous literature. This study is novel as it sheds light on PRERs and firms' performance from the environmental perspective. Previous studies have made preliminary analysis of REACH and firms' production behaviour, but empirical analysis has not been conducted yet. Second, previous studies on the Porter Hypothesis were conducted 
mainly for developed countries, while this study uses firm-level data for developing countries_-Vietnam and Malaysia. Both countries have experienced remarkable economic growth in the last few decades, but their peoples' income status ranges from lower- to higher-middle income, thereby presenting diversity in the technological level. Finally, this study focuses on the direct and indirect effects of PRERs on productivity. Although existing studies merely analysed the indirect effect, this study can more accurately analyse PRERs' effect on productivity by identifying the mechanism.

The remainder of this paper is organized as follows. Section 2 provides the background of environmental regulations, innovation, and PRERs. Section 3 briefly reviews literature. Section 4 reviews Malaysia and Vietnam's economic performance and regulations. Section 5 proposes empirical models and describes the dataset. Section 6 presents the empirical results and implications followed by robustness tests. Finally we conclude in Section 7.

\section{Background}

\subsection{The RoHS Directive and REACH Regulation}

Adopted in February 2003 by the EU, RoHS specifically prohibits the inclusion of six major hazardous substances ${ }^{1}$ in electric and electronic products on the market to prevent health hazards of workers engaged in recycling and environmental pollution caused by illegal dumping. Four additional substances ${ }^{2}$ made the list on 31 March, 2015. Following the EU, Asian countries such as Japan and China have adopted their own versions of RoHS - the J-MOSS and China RoHS in 2006 and 2007, respectively.

\footnotetext{
1 The hazardous substances include mercury, lead, cadmium, hexavalent chromium, polybrominated biphenyl, and polybrominated diphenyl ether.

2 The additional substances include bis (2-ethylhexyl) phthalate, butyl benzyl phthalate, dibutyl phthalate, and diisobutyl phthalate.
} 
REACH began in June 2007 as a system for comprehensive registration, evaluation, approval, and restriction of chemical substances in Europe, and its candidate list of substances has been revised since its adoption. Its primary goal is to replace substances of high concern with economically and technically feasible alternative substances and technologies. Additionally, firms, importers, and downstream firms are obligated to assure there are no adverse effects on the environment and health upon use of their manufactured chemical substances and products. REACH also stimulated Asian countries to adopt their own versions_-Japan's "Kashinhou" (Chemical Substances Control Law) and China's REACH (Measures for Environmental Management of New Chemical Substances).

One characteristic of PRERs, which are regulatory instruments for environmental protection, distinguishing them from traditional environmental regulations is that they regulate product attributes. That is, firms selling products to countries regulated by PRERs irrespective of the location are required to comply with such regulations. Therefore, unlike traditional regulations focusing on control of domestic firms' polluting activities, PRERs such as RoHS and REACH affect firms both within and outside the regulating countries and require supply chain management of the product attributes across borders.

Another comparison can be made between PRERs and voluntary environmental actions such as ISO14001. According to Arora and Gangopadhyay (1995), firms can increase their profits by complying with voluntary instruments to respond to the new generation willing to pay higher prices for environment-friendly products. Although PRERs are compulsory regulations, firms will not comply with them for the same reason as voluntary actions. Then, what motivates Malaysian and Vietnamese firms, 
located far from the EU, to comply with EU's PRERs? One explanation may lie in the abovementioned characteristic of PRERs. That is, firms that not only sell their final goods to the EU but also downstream sell final goods to the EU face pressure to comply with the EU's PRERs. Therefore, firms from ASEAN countries may be compelled to respond to their customers' requirements. An alternative explanation may be that firms want to reinforce their advantage in the EU market as PRERs help them increase or quality-upgrade their exports. As Arimura et al. (2014) indicates, PRERs can have potentially significant impacts, such as requiring improvement of quality control in firms that export to the EU or are part of global value chains in developing countries. These two hypotheses will be tested in the following sections.

\subsection{Conceptual Framework: Firms' Reaction to Environmental Regulations}

Typically, risk-averse firms under pressure from environmental regulations would choose to either relocate to a developing country with looser regulations or keep serving the developed market if they find it more profitable despite the compliance costs. The former case is called the pollution haven hypothesis and raises concerns regarding the "race to the bottom" phenomenon in developing countries. Firms may choose the latter option because of the reputation obtained from compliance with environmental regulations. Cavaliere (2000) concluded that in a two-period or repeated finite game, firms can build an environmental reputation if consumers' information is imperfect with regard to quality and incomplete with respect to environmental constraints that may affect the firms' behaviour.

As regards environmental regulations and innovations, Innes and Bial (2002) found that some firms choose to overcomply with environmental regulations. They justified this behaviour using a Bertrand competition model and concluded that an environmental 
tax that is efficient ex post provides incentives for overinvestment in $R \& D$, as firms hope to gain profits by affecting regulatory levels and impose costs on other firms. Ford et al. (2014) found that overcompliance is a competitive strategy to gain technological advantage over competitors while bolstering social licenses to operate.

According to the standard neoclassical theory, (strict) environmental regulation adversely affects productivity and competitiveness by imposing constraints on industry behaviour. On one hand, firms face direct costs such as end-of-pipe equipment or R\&D investment necessary to modify production activities. On the other hand, firms' budgets are limited due to financial constraints. By committing resources to comply with environmental regulations, firms also incur indirect (opportunity) costs because they cannot invest in other profitable endeavours (Ambec et al., 2013). The claim that well-designed environmental regulations promote technological innovation so productivity may be improved is known as "the Porter Hypothesis." Formulated by Porter and van der Linde (1995), this theory accounts for relationships among environmental regulation, innovation, and competitiveness.

Regarding the mechanism of the Porter Hypothesis, Porter and van der Linde $(1995)^{3}$ gave six reasons why properly crafted regulations may lead to these outcomes. The incentive of overcomplying with environmental regulations also can be the explanation. This incentive may trigger perpetual efforts from firms in terms of innovation for gaining additional benefits, such as raising costs for rivals or gaining technological advantages.

The Porter Hypothesis has triggered significant empirical investigation since the early 1990s. Jaffe and Palmer (1997) pointed out the ambiguity in the hypothesis's definition

\footnotetext{
${ }^{3}$ For details, see Porter and van der Linde (1995, pp. 99-100).
} 
and classified it into three versions: (1) the weak version of Porter Hypothesis (WPH): environmental regulations may stimulate technological innovation (irrespective of improvement in competitiveness); (2) the strong version of Porter Hypothesis (SPH): improvement in productivity stemming from technical innovation stimulated by environmental regulations may bring greater benefits than regulatory compliance costs; and (3) the narrow version of Porter Hypothesis (NPH): well-designed environmental regulations promote innovation and have less negative impact on productivity than direct regulation.

Among studies examining NPH regarding traditional environmental regulations, many obtained supportive results. Most empirical studies examining WPH obtained positive conclusions, but results were mixed for those examining SPH. Rubashkina (2015) found evidence of a positive impact of environmental regulation on innovation activity output, thus supporting WPH, but found no evidence concerning $\mathrm{SPH}$, as productivity appears unaffected by the degree of pollution control and abatement efforts. Rexhäuser and Rammer (2014) found that SPH does not generally hold but depends on the type of environmental innovation. The empirical analysis of this study focuses on both WPH and SPH for the two EU PRERs.

\subsection{Conceptual Framework: Role of PRERs in the Context of the Porter}

\section{Hypothesis}

Although PRERs have distinguishing characteristics compared with traditional environmental regulations, their equal focus on environmental and consumer protection further makes the innovation-promoting effect of RoHS and REACH more ambiguous. Regarding applicability of the Porter Hypothesis to RoHS and REACH, would the hypothesis hold even when environmental regulations are designated to protect 
consumer safety? Our answer is positive. As Cavaliere (2000) indicated, firms can choose to comply with environmental regulations to build an environmental reputation when they believe consumers have imperfect information about quality or environmental constraints. Here, firms may have incentive to overcomply with regulations to gain a reputation advantage among consumers; for example, firms may feature their additive-free products to cater to the increasing health consciousness of consumers from developed countries. This underlying incentive may make regulations focused on consumer safety protection (e.g. RoHS and REACH) have an innovation-promoting effect, although literature has not proven this. Regarding other literature, Frohwein and Hansjurgen (2005) argued that REACH would have different impacts on various chemical industry segments, of which some may suffer negative impacts on competitiveness. However, Ackerman and Massey (2004) pre-assessed REACH to conclude it will not harm the chemical sector's innovation level but rather boost innovation and competitiveness. Typically, new regulation entails significant implications regarding competition for companies downstream, while the PRERs' pressure may also be transmitted indirectly to upstream suppliers through the global value chain. Consequently, there is no consensus on how PRERs will impact competition and innovation.

\section{Literature Review}

\subsection{Environmental Regulations, Innovation, and Productivity}

Empirical studies to date have focused on estimating the relationship between environmental regulations and innovation. Regarding the effect of environmental policies on inducement of innovation, many previous studies have shown supportive 
results. Yang, Tseng, and Chen (2012) showed that pollution abatement fees, a proxy for environmental regulations, are positively related to R\&D expenditure, implying that stronger environment protection induces $R \& D$. That is, although environmental regulations are introduced and strengthened, many firms do not immediately relocate overseas to where environmental regulations are relatively loose. However, although most agreed with inducing innovation through economic means such as environmental taxes, this is not necessarily supported by quantitative analysis. Kemp and Pontoglio (2011) concluded that selection of the means of environmental policy does not have a decisive influence on innovation compared with the strength of that policy. Although environmental taxes are often effective for progressive technology dissemination, very few research results showed breakthrough innovation. For example, for effective implementation of an environmental tax based on emission amounts, the tax rate must be increased, but introducing high environmental tax is not realistic.

However, empirical research pointed out that regulation has a negative effect on firm profits, and productivity does not fully consider dynamic aspects of the Porter Hypothesis. Lanoie et al. (2008) showed that severe environmental regulation leads to productivity improvement over the long term by introducing a three- or four-year lag in the relationship between the intensity of environmental regulation and productivity. Regarding innovation and productivity, Yang and Chen (2012) focused on the mutual effects of innovation, productivity, and export using Indonesian data, and development of innovation significantly increased both firm productivity and export. Franco and Marin (2017) suggested that downstream stringency is the most relevant driver of innovation and productivity, while within-sector regulations only affect productivity but not innovation. 


\subsection{Product-related Environmental Regulations}

Due primarily to the limited designated data surveys, there are only few empirical studies on PRERs. Most of these studies use IDE-JETRO's firm-level dataset on firms' response to the selected PRERs in Vietnam and Malaysia. Otsuki et al. (2014) showed that while RoHS and REACH raise compliance cost at the similar level, they facilitate the entrance of only previously non-exporting firms into export markets but do not affect incumbent exporters' activities. Arimura et al. (2014) used the same dataset and verified the relationship between firm's compliance with PRERs and acquisition of certification of an environmental management system. The same dataset is used in Michida et al. (2014) and Michida and Nabeshima (2014) for their case studies on the determinants of compliance with PRERs.

\section{Economic Performance and Regulations of Hazardous Chemicals in Malaysia and Vietnam}

Exports of goods and services from Malaysia and Vietnam have grown rapidly during the past two decades. Although Malaysia is a larger exporter than Vietnam, exports from both countries have been increasing rapidly, especially in the period after Vietnam joined the World Trade Organization in 2007 . Our data show that $70 \%$ and $74 \%$ of sampled firms in Malaysia and Vietnam, respectively, exported their products.

Rapid growth in the number of both domestic firms and multinational corporations (MNCs) has been observed, especially in Vietnam, since 2000, and increased foreign direct investment and export has put greater pressure on Malaysian and Vietnamese firms to comply with safety and quality regulations. After the introduction of RoHS, an increasing number of countries implemented their own RoHS standards. Vietnam 
introduced its RoHS in September 2011. Malaysia also has a long history of regulating hazardous chemicals. According to IMF, Direction of Trade Statistics Yearbook 2016, the EU has been an extremely important trade partner for ASEAN countries, as it accounts for one of the largest exports (11.4\% of total and $15 \%$ of external exports, respectively) in the ASEAN area. Thus, Malaysian and Vietnamese firms are well aware of the importance of the EU's regulations on hazardous chemicals. Among respondent firms in Malaysia and Vietnam, $81 \%$ and $88 \%$, respectively, achieved compliance with RoHS by 2011; additionally, 70\% (in Malaysia) and 87\% (in Vietnam) achieved compliance with REACH by 2011.

\section{Empirical Analysis}

\subsection{Empirical Methodology}

We consider productivity as the realization of innovation and examine the effect of PRERs on R\&D and productivity through three steps. The first two steps adopt the approach developed by Hamamoto (2006): We first examine the determinants of R\&D, focusing on the influence of PRERs (i.e. WPH) and, second, examine the impact of induced R\&D on productivity (i.e. SPH). It should be noted that since the second step uses PRER-induced R\&D expenditure, it represents the indirect impact of PRERs on productivity. In the third step, we examine the direct impact of PRERs by regressing PRERs directly on the productivity. These three estimation equations represent the mechanism through which PRERs affect R\&D and productivity, as discussed in the conceptual framework.

(i) Impact of PRERs on R\&D expenditure

First, we estimate the impact of PRERs on R\&D expenditure. The dependent variable 
is $R \& D$ expenditure, while only limited observations are available (168/1,425 firms), which may raise concerns of a potential selection bias. $R \& D$ expenditure is measured as the percentage of total sales without specific classification, and the missing values mainly result from firms' non-response. To address the potential selection bias, we use the Heckman two-stage estimation method to examine the determinants of R\&D cost. In the Heckman model, dummy variables of the $\mathrm{MNC}$, denoted by $M N C$ (=1 if the firm is an MNC), and number of years since the firm's establishment as of the survey, denoted by Age, are used as exclusion restrictions. Un and Cuervo-Cazurra (2008) mentioned that foreign MNCs' subsidiaries are less likely to invest or report their amount of R\&D than domestic firms, so $M N C$ controls the effect of different capital ownership types. Furthermore, young firms may be more willing to respond to government surveys since they may face stricter regulations. As demonstrated in the subsequent section, both $M N C$ and Age show significance and expected signs in the first step's regression of the Heckman model for non-response to R\&D expenditure, but show insignificance in the second step. From the first step, we obtain the inverse mills ratio that was included in the main model. The inverse Mills ratio, however, was insignificant, indicating that selection bias due to non-response in the dependent variable can be ruled out.

Based on traditional formulation of this research, such as Yang et al. (2012), the explanatory variables are classified into three categories: firm characteristics, international influences, and environmental regulations such as PRER variables. Analysis of determinants of R\&D expenditure is based on Eq. (1).

$$
\begin{aligned}
\ln R D_{i} & =\beta_{0}+\beta_{1} P R E R_{i}+\beta_{2} \ln E M P_{i}+\beta_{3} \ln C A P I_{i} \\
& +\beta_{4} \ln A S S E T_{i}+\beta_{5} E X P R_{i}+v_{i} .
\end{aligned}
$$


Here, subscript $i$ is the firm number, and $R D$ is R\&D expenditure ${ }^{4}$. PRER is the dummy variable indicating whether the firm met RoHS (or REACH). The survey asked ASEAN firms if they can/cannot/do not try to meet the regulations, and PRER equals one if and only if the firm can meet the PRER. Since a positive correlation was confirmed between environmental regulation and $R \& D$ cost in previous studies, it is expected that $\hat{\beta}_{1}$ takes a positive value. EMP is number of employees, CAPI is capital intensity (total capital divided by number of employees ${ }^{5}$ ), and ASSET is the asset-to-total sales ratio. It is expected that capital intensity is positively related to $R \& D$ expenditure, as capital-intensive industries generally need to benefit more from technological innovation and thus are active in developing new technologies or processes (Yang et al., 2012). ASSET is included as a proxy for capital-intensive production. R\&D investment is expected to be higher in firms whose products have high capital requirements. EXPR is the export-to-sales ratio indicating international influences. This variable is included because firms that export generally have higher productivity through $\mathrm{R} \& \mathrm{D}$ and are thus characterized as having higher innovation propensities. Moreover, export is an important element of their economic development. Many Southeast Asian countries are part of global value chains, which means that their goods from manufacturing sectors are exported to developed economies. Finally, a Malaysia dummy is included to control for country-level heterogeneity, and $v_{i}$ is the error term.

(ii) Impact of induced R\&D on total factor productivity (indirect impact of PRERs)

If the PRER dummy is significant in the first step, that is, there is significant induced

\footnotetext{
${ }^{4}$ R\&D expenditures of Vietnamese firms are denominated in Malaysian Ringgit. The exchange rate is fixed at $1 \mathrm{VND}=0.00015 \mathrm{MYR}$.

${ }^{5}$ Since it seems reasonable to assume that a firm's capital is proportional to its assets, we use assets as a proxy for capital in this study.
} 
R\&D by PRERs, then the effect of induced R\&D on productivity is examined as follows:

$$
\ln T F P_{i}=\gamma_{0}+\gamma_{1} \ln R D_{i}+\gamma_{2} \ln C A P I_{i}+\mu_{i}
$$

$\widehat{R D}$ here denotes PRER-induced R\&D from estimating Eq. (1). Using coefficient $\hat{\beta}_{1}$ estimated from Eq. (1), it is calculated as

$$
R D_{i}=\left[\widehat{\beta}_{1} /\left(1+\widehat{\beta}_{1}\right)\right] * R D_{i}
$$

TFP in Eq. (2) measures the productivity of a firm. This study uses cross-sectional data, making it impossible to apply panel data-based methods of total factor productivity (TFP) estimation, such as that of Levinsohn and Petrin (2003). Alternatively, we adopt the measure proposed by Matsuura et al. (2008), which measures deviation of a firm's TFP from that of the average firm, as follows:

$$
\ln T F P_{i}=\ln T F P_{a}+\ln \frac{Y_{i}}{Y_{a}}-\frac{1}{2}\left(S_{L_{i}}+S_{L_{a}}\right) \ln \frac{L_{i}}{L_{a}}-\frac{1}{2}\left(S_{K_{i}}+S_{K_{a}}\right) \ln \frac{K_{i}}{K_{a}}
$$

$Y$ is the real added value of the firm, $K$ is real capital stock, $S_{L}$ is the labour cost share of the firm, and $S_{K}$ is the capital cost share of the firm. Subscript $a$ denotes the average firm. Other variables are the same as those described above. In Eq. (2), if $p_{1}$ is found significant, it is confirmed that RoHS (or REACH) has a statistically significant indirect effect on TFP.

(iii) (Direct) Impact of PRERs on TFP

Following Gray and Shadbegian (2003), who examined SPH and the direct effect of environmental regulation on productivity, we specify our model as follows:

$$
\ln T F P_{i}=\delta_{0}+\delta_{1} P R E R_{i}+\delta_{2} \ln R D_{i}+\delta_{3} \ln C A P I_{i}+\xi_{i}
$$


This specification allows us to examine the direct effect from RoHS or REACH to TFP. If $\delta_{1}$ is found to be significant, PRERs' direct effect on productivity is confirmed, and if $\delta_{2}$ is found to be significant, $\mathrm{R} \& \mathrm{D}$ expenditure affects productivity, regardless of the product-related environmental regulation.

\subsection{Data}

The cross-sectional data collected by the IDE-JETRO research project, "Impact of product-related environmental regulations on international trade and technological spillovers through supply chain in Asia", ${ }^{\prime \prime}$ is used in this study. All firm characteristics are for the previous completed year before the survey was implemented. Malaysia and Vietnam were chosen as the research settings for the following reasons. First, many Southeast Asian countries are part of global value chains for various manufacturing sectors; thus, firms in this region are more likely to be affected by PRERs. Second, the countries' level of economic development is appropriate for examining the impact of PRERs. If a country is well below a certain level of development, the impact, if any, may be subtle.

Use of cross-sectional data on $R \& D$ expenditure may raise the question of endogeneity in PRER compliance. The first concern may be regarding reverse causality between R\&D expenditure and PRER compliance. If R\&D activities are implemented simultaneously with the PRER compliance process, R\&D expenditures may have a significant effect on the PRER dummies. Regarding this issue, we summarized the number of years it took firms to comply with PRERs. The result shows that about $60 \%$ firms in both countries took less than one year to meet RoHS and REACH, and more

\footnotetext{
6 The survey was implemented for firms in Malaysia (November 2012 to February 2013, Penang State) and Vietnam (November 2011 to January 2012, nationwide) by distributing survey tables that classified the data into four categories: 1) basic information, 2) input procurement and certificates, 3) chemical management, and 4) export status.
} 
than $90 \%$ firms achieved compliance within three years. There is no significant difference between the years of compliance of RoHS and REACH. Since both PRERs were adopted in the 2000s, which is at least four years before the survey, most firms had finished the process of compliance as of the survey year.

Another underlying endogeneity problem exists if firms refuse to comply with PRERs when they find it profitable not to serve the EU market to benefit from saving the compliance cost. However, such hypothesis requires that firms have the ability to keep running even after losing trade partners in the EU or whoever sells products to the EU. In our sample, the percentage of firms selling products to the EU is about $30 \%$ and $60 \%$ for Malaysia and Vietnam, respectively. Moreover, the average export-to-sales ratio also accounts for a large percentage in both countries. Thus, it seems difficult, especially for small firms that account for the larger percentage of firms in Malaysia $(83.4 \%)$ and Vietnam (57.6\%), to exit the EU market. As a further test of the exogeneity of PRER compliance, we follow Topalova and Khandelwal (2011) and examine the correlation of compliance with firm performance. We regress the compliance with PRERs on a number of firm characteristics. The insignificant coefficients suggest an exogenous compliance with PRERs.

\subsection{Summary Statistics}

The survey focuses on a variety of Malaysian and Vietnamese industries. Table 1 presents the industries studied and count of firms. Industries typically targeted for RoHS and REACH are denoted by “०.” Specifically, we define manufacturing firms as those belonging to all industries, except "Wholesale and retail trade and repair" and "Others". Table 2 shows descriptive statistics of the variables by country. R\&D expenditure, capital intensity, and TFP, as well as number of years since the firm's establishment, are 
higher in Malaysia. These perhaps reflect the higher economic growth and industrialization of Malaysia. While capital intensity is higher in Malaysia, Vietnam has larger average firm size in terms of number of employees. The fraction of MNCs and export-to-sales ratio are also greater in Vietnam. Finally, regarding compliance with RoHS and REACH, Malaysia and Vietnam have similar ratios of complying firms. However, because we regard the absence of report to compliance as a missing value and the number of Vietnamese firms is about three times that of Malaysian firms, similar observations in Malaysia and Vietnam imply that Malaysia has far higher percentage of firms achieving RoHS/REACH compliance.

$<$ Table 1 inserted here $>\quad<$ Table 2 inserted here $>$

\section{Empirical Results}

\subsection{Impact of PRERs on R\&D}

Table 3 shows results of PRERs' effect on R\&D expenditure corresponding to Eq. (1). Columns 1-3 and 4-6 correspond to the results for RoHS and REACH, respectively. For each PRER, we control for industry and firm fixed effects.

$<$ Table 3 inserted here $>$

The result is rather surprising for RoHS; no coefficient in the estimated models is significant, implying that RoHS has no significant effect on R\&D expenditure. Although RoHS regulates the inclusion of six hazardous substances in electrical and electronic equipment, the range of regulated substances is relatively narrow, as mentioned in Section 2.1. Therefore, firms dealing with products other than electrical and electronic equipment may lack incentive to comply with RoHS, and even firms handling electrical and electronic equipment may flexibly shift to alternative raw 
materials that are not regulated by RoHS.

For REACH, the most notable point is that $R E A C H$ is significant in all models. The effects on R\&D vary across the models. The coefficients range around 0.95 to 1.22 , indicating $95-122 \%$ higher R\&D expenditure for firms complying with REACH. At first glance, the coefficients of REACH may be relatively large, as R\&D expenditure of REACH compliers is about two times higher. However, the average R\&D-to-sales ratio for Malaysian firms is $15 \%$ and only $6 \%$ for Vietnamese firms, indicating the reasonable coefficients of REACH on R\&D expenditure. Moreover, as mentioned in Section 2.3, firms under certain conditions would have incentive to overinvest in R\&D to increase their rival's costs, which may be reflected on the large coefficients of REACH. Why does REACH, compared with RoHS, have a positive influence on firms' R\&D expenditure? This may be accounted for by the characteristics of REACH Regulation. REACH regulates inclusion of more than 1,500 substances and imposes strict restrictions on all products exported to the EU. The wider target substances and target products impose pressure on firms to undertake innovation activities.

Regarding the country dummy, the significant and positive coefficients in all models imply that Malaysian firms invest more in R\&D than Vietnamese firms. Moreover, $E M P, C A P I$, and $E X P R$ are positively significant at the $1 \%$ level in determining R\&D expenditure ${ }^{7}$. This means that firms with more employees, higher capital intensity, and export intensity invest more in R\&D. The negatively significant coefficient for ASSET contradicts a prior expectation, possibly because $A S S E T$ is also an indicator of entry barriers to some degree. In sectors with high capital requirements, entry is limited because of potentially sunk costs (Rexhäuser and Rammer, 2014), and R\&D investment

\footnotetext{
${ }^{7}$ EXPR is not significant in the REACH case, however.
} 
decreases as there is less incentive to gain technical and reputation advantage. It is conceivable that the demand of compliance with PRERs positively depends on the number of employees, capital intensity, and export intensity and negatively depends on the asset-to-sales ratio.

To summarize, differences in the type of contained substances regulated by RoHS and REACH cause different effects on firms' innovation. These findings are consistent, at least for REACH, with the claims of WPH regarding the positive relationship between stringent environmental policies and R\&D.

\subsection{Impact of PRERs on Productivity}

\subsubsection{Indirect Impact}

Table 4 shows the results of PRERs on productivity. Columns 1-3 are for the estimations of Eq. (2), that is, indirect impact of PRERs on TFP using the full sample, samples of manufacturing firms, and firms belonging to REACH targeted industries, respectively. Again, we control for the industry and firms' fixed effects for each PRER. We only test the indirect effect of REACH on TFP because RoHS had no effect on $\mathrm{R} \& \mathrm{D}$ in the previous analysis.

$<$ Table 4 inserted here $>$

This subsection focuses on the impacts of PRER-induced R\&D on TFP, testing whether SPH is supported by our data. Since REACH is found to have significant R\&D enhancement effects, as shown in Section 6.1, we first calculate the amount of REACH-induced R\&D (i.e. "RD") and its share of total R\&D based on Eq. (3). It can be confirmed that the coefficient for REACH-induced R\&D takes value around 0.25 at the $1 \%$ significance level, implying that PRER-induced R\&D does contribute to TFP increase. This finding is consistent with the Japanese case in Hamamoto (2006) and the 
Taiwanese case in Yang et al. (2012) that supported the Porter Hypothesis of a possible win-win situation. That is, stringent environmental regulation can indirectly promote firms' competitiveness in terms of productivity through induced R\&D activity.

Furthermore, coefficients of $C A P I$ and the country dummy are also statistically significant. This indicates that there is significant evidence that firms with higher capital intensity, especially Malaysian ones, tend to have higher competitiveness.

\subsubsection{Direct Impact}

This subsection further examines SPH from the perspective of PRERs' direct effects on firm's TFP to provide insights into how PRERs affect TFP. As shown in Columns 4-6 of Table 4, RoHS has no significant direct effect on TFP, while Columns 7-9 show that the coefficient for REACH takes negatively significant values around -0.45 . However, R\&D expenditures are positively significant at the $1 \%$ level for both RoHS and REACH, and the coefficients range around 0.35 , which is reasonably larger than those of REACH-induced R\&D (i.e. " $R D$ ") shown in Columns 1-3. That is, compliance to REACH itself will have a negative impact on TFP, while R\&D investment significantly increases firms' $\mathrm{TFP}^{8}$.

\subsection{Robustness Checks}

\subsubsection{Alternative Measure of PRERs}

Here, we examine limitations of the PRER classification and firm survey data. First, our results may be sensitive to the measure of PRERs, especially regarding regulations targeted to similar industries. Therefore, the first robustness check introduces an alternative measure. We define a new dummy variable named "RorR" (=1 if the firm has compliance to either RoHS/REACH, otherwise $=0$ ) to replace RoHS/REACH

\footnotetext{
8 These results support the Porter Hypothesis: "properly designed environmental standards can trigger innovation that may partially or more than fully offset the costs of complying with them" (Porter and van der Linde, 1995, p. 98).
} 
dummies of Eq. (1) ${ }^{9}$. As Columns 7-9 of Table 3 show, RorR is significant in all Heckman models at least at the 5\% level. The magnitudes range between 0.9 to 1.2 , which are almost the same for the REACH dummy, while standard errors are slightly smaller compared with the REACH case. Since RoHS had no effect on R\&D expenditure, this new measure totally captures the effects of REACH. This indicates that our results show no sensitivity to the measure of PRERs.

\subsubsection{Treatment on Missing Values}

Because of the rather small sample size, our results need a robustness check. If the way missing values occur is purely random, the result should remain stable. However, if the values are missing systematically, the results may be biased. The missing value problem tends to occur primarily in R\&D expenditure and PRER dummies. The RoHS and REACH dummies, the key variables of this study, have less than 300 out of 1,425 observations, and $\mathrm{R} \& \mathrm{D}$ expenditure data, wherein the problem is more severe, has less than 200. This implies that missing values tend to occur systematically. Regarding the data-gathering process, $R \& D$ expenditure and PRER dummies are unique compared with other variables; that is, some firms may choose not to respond. Thus, we replace these missing values with zeros and re-examine Eq. (1) to test our results' robustness.

Typically, as the dependent variable is the logarithmic form, the Poisson pseudo-maximum likelihood (PPML) model is employed to deal with zero R\&D expenditures. Moreover, the interaction term of the country dummy and PRER is included as an additional variable to examine the difference between two ASEAN countries $^{10}$. The last three lines of Table 2 show summary statistics for the two variables.

\footnotetext{
9 We did not include RoHS and REACH dummies into Eq. (1) because of high correlation $(\operatorname{Cor}(R o H S, R E A C H)=0.582)$ between the two variables, which may raise the multi-collinearity problem.

${ }_{10}$ We do not include this interaction term in our regressions because the sample size becomes even smaller, which critically reduces the reliability of the analysis.
} 
The means of each variable are much smaller than the original ones. After the treatment of non-response, only $10 \%-30 \%$ of firms can meet PRERs in both countries, while $70 \%-90 \%$ could in the original data. R\&D expenditure of firms also decreased as expected.

Table 5 shows the marginal effects of the PPML model estimations for RoHS and REACH. The marginal effects of RoHS remain insignificant, irrespective of whether the interaction term is included (Columns 1-6). No significant effect is found from RoHS to R\&D expenditures. As for REACH, the coefficients remain significant at least at the 5\% level in all cases. In cases without interaction terms (Columns 7, 9, and 11), the marginal effects of REACH range around 1.2, which are not significantly different from those of the original estimations. These results indicate that for non-response of R\&D and compliance with PRERs, the response to REACH still can create incentives for firms to advance R\&D. A notable fact is shown by cases that include interaction terms (Columns 8, 10, and 12). While all REACH and interaction terms are significant at least at the $5 \%$ level, the magnitudes of $R E A C H$ terms become about two times larger (around 2.4), and magnitudes of the interaction terms also range around 2.1, whose absolute values are slightly smaller than those of $R E A C H$ terms. These results imply that REACH does trigger R\&D activities in both countries, while the inductive effect is much stronger in Vietnamese firms. One underlying reason may be the export status. The percentage of Malaysian firms belonging to global supply chains is $52 \%$, while it is $100 \%$ for Vietnamese firms. The same applies for the ratio of selling main products to the EU: Vietnamese firms (59\%) have two times higher ratio compared with Malaysian firms (32\%). The export-to-sale ratio, which is $25 \%$ higher in Vietnam, also supports this conclusion. 
$<$ Table 5 inserted here $>$

\subsection{Input Change and Markup Effects}

As Sections 5.1 and 5.2 show, RoHS and REACH have significantly different impacts on firms' innovation and productivity; this subsection discusses and investigates the reasons.

\subsubsection{Input Change}

One reason may be the difference in the regulation range of substances. RoHS only prohibited six types of hazardous substances (the survey was implemented before four additional substances made the list in 2015). Compared with REACH, whose coverage is much wider, firms can comply with RoHS by only substituting the six prohibited substances with legal inputs. That is, it is much easier for firms to comply with RoHS than REACH. To investigate the impact of PRERs on input changes, we employ the approach of Bas and Strauss-Kahn (2015). In our model, the dependent variable is the dummy indicating the firm has changed the input to meet the specific PRER. The dependent variables include the RoHS/REACH dummy and two covariates - the country dummy and $\ln E M P$ to control for nationality and firm size, respectively.

Columns 1-2 of Table 6 show that compliance with RoHS or REACH has different impacts on input change. While RoHS has a positive impact at the 5\% level, REACH has no significant effect. This indicates that firms can respond to RoHS by substituting the inputs, which corresponds to the conclusion that RoHS does not induce R\&D. However, as REACH restricts more substances than RoHS and the candidate list of substances has been frequently revised during the past 10 years, compliers must innovate rather than change the input, which results in an increase in $R \& D$ expenditure and further increases productivity. This analysis helps explain the different impacts of 
RoHS and REACH on innovation and productivity.

$<$ Table 6 inserted here $>$

\subsubsection{Price Change}

Further interests lie in the evolution of exported product quality (price) after compliance with the specific PRER. The hypothesis is that firms may choose to comply with specific PRERs that can induce a quality upgrade of their products, which can be observed as a markup in the product. If so, then the markup is caused by spillover of innovations aimed at compliance. To investigate the motivation of firms to comply with PRERs, we use the ordered probit model to regress the discrete variable, which indicates the change of product price by taking an integral value from 1 to $3(=1 /=2 /=3$ for there being a decrease/no change/increase in product price, respectively) on the PRER dummies, the country dummy and $\ln E M P$.

According to the results in Columns 3-4 of Table 10, neither RoHS nor REACH has significant effects on price changes in firms' products, meaning that neither PRER can lead firms to upgrade their products through compliance. The EU PRERs, whose initial goal is to protect consumer health, do not reflect an improvement in product quality. Facing the pressure of PRERs, firms have no choice but to change their export destination or comply in order to keep exporting. For RoHS, compliers can meet the directive by input change, which will neither induce R\&D activity nor raise productivity. As for REACH, compliers must innovate irrespective of a quality upgrade of the product, and induced R\&D will allow firms to meet REACH followed by an increase in productivity.

\section{Concluding Remarks}


This study examined the impact of the two PRERs of the EU-RoHS Directive and REACH Regulation - on Malaysian and Vietnamese firms' performance in line with the weak and strong versions of the Porter Hypothesis. In the analysis, productivity is considered as the realization of innovation, and the R\&D enhancement effect of PRERs is investigated, focusing on their consequences: indirect influence on productivity through R\&D enhancement and direct relationship between PRERs and productivity. The result shows that REACH can create an incentive for firms to advance R\&D and that it raises productivity. This finding is supportive of both the weak and strong versions of the Porter Hypothesis. However, the relationship between the response to RoHS and R\&D expenditure is not confirmed. Despite some exceptions, this study provided empirical evidence that the innovation-promoting effect, which was proposed in the Porter Hypothesis for environmental regulations, can hold for regulations focusing on protection of consumer safety. Thus, the mechanism of the Porter Hypothesis is generalized to a wider set of regulations ${ }^{11}$. Further analysis showed that firms comply with RoHS and REACH in different ways, and compliance will not result in upgrade in product quality. In line with Otsuki et al. (2014), we conclude that firms choose to comply with RoHS and REACH just to ensure continuous exports to the EU market instead of enhancing the amount of export or quality of products.

Further analyses focusing on a wider range of PRERs, particularly, those using panel data collected from the entire global value chain, would be necessary to make useful prescriptions for investigating the more precise effects of PRERs both within and outside the regulating countries.

\footnotetext{
${ }^{11}$ As mentioned in the introduction and background, although it is possible for the Porter Hypothesis to hold in ELV and WEEE, we are forced to give up the examination due to limited observations of the two PRERs.
} 
Given that consumers continue to demand higher product safety, it is expected that adoption of PRERs will keep expanding the world market in the future. In Asia, similar regulations have been introduced in the last decades. Thus, it is recommended to discuss coordination of regulatory policies that would mutually benefit countries in this region. Therefore, regulation of chemical substances from the EU such as RoHS/REACH regulations could be a touchstone for regional or worldwide coordination of PRERs.

\section{References}

Ackerman, F. and R. Massey (2005), The True Costs of REACH, Copenhagen: Nordic Council of Ministers.

Ambec, S., M. Cohen, S. Elgie, and P. Lanoi (2013), 'The Porter Hypothesis at 20: Can environmental regulation enhance innovation and competitiveness?', Review of Environmental Economics and Policy 7(1): 2-22.

Arimura, T., H. Iguchi, and E. Michida (2014), 'Product-related environmental regulation and voluntary environmental actions: Impacts of RoHS and REACH in Malaysia', IDE Discussion Paper No. 454, Institute of Developing Economies, Chiba, Japan.

Arora, S. and S. Gangopadhyay (1995), 'Toward a theoretical model of voluntary overcompliance', Journal of Economic Behavior and Organization 28(3): 289-310.

Bas, M. and V. Strauss-Kahn (2015), 'Input-trade liberalization, export prices and quality upgrading', Journal of International Economics 95: 250-262.

Cavaliere, A. (2000), 'Overcompliance and voluntary agreements', Environmental and Resource Economics 17(2): 195-202. 
Chatzistamoulou, N., G. Diagourtas, and K. Kounetas (2017), 'Do pollution abatement expenditures lead to higher productivity growth? Evidence from Greek manufacturing industries', Environmental Economics and Policy Studies 19: 15-34.

Ford, J. A., J. Steen, and M. L. Verreynne (2014), 'How environmental regulations affect innovation in the Australian oil and gas industry: going beyond the Porter Hypothesis', Journal of Cleaner Production 84: 204-213.

Franco, C. and G. Marin (2017), 'The effect of within-sector, upstream and downstream environmental taxes on innovation and productivity', Environmental and Resource Economics 66: 261-291.

Frohwein, T. and B. Hansjürgens (2005), 'Chemicals regulation and the Porter Hypothesis - A critical review of the n European chemicals regulation', Journal of Business Chemistry 2(1): 19-36.

Gray, W. B. and R. J. Shadbegian (2003), 'Plant vintage, technology, and environmental regulation', Journal of Environmental Economics and Management 46(3): 384-402.

Hamamoto, M. (2006), 'Environmental regulation and the productivity of Japanese manufacturing industries', Resource and Energy Economics 28: 299-312.

Innes, R. and J. Bial (2002), 'Inducing innovation in the environmental technology of oligopolistic firms', Journal of Industrial Economics 50(3): 265-287.

Jaffe, A. B. and K. Palmer (1997), 'Environmental regulation and innovation: A panel data study', Review of Economics and Statistics 79: 610-619.

Jorgenson, D. W. and P. J. Wilcoxen (1990), 'Environmental regulation and US economic growth', RAND Journal of Economics 21(2): 314-340. 
Kemp, R. and S. Pontoglio (2011), 'The innovation effects of environmental policy instruments - A typical case of the blind men and the elephant', Ecological Economics 72: 28-36.

Lanoie, P., M. Patry, and R. Lajeunesse (2008), 'Environmental regulation and productivity: New findings on the Porter Hypothesis', Journal of Productivity Analysis 30: 121-128.

Michida, E. and K. Nabeshima (2014), 'Role of supply chains in adopting product related environmental regulations: Case studies of Malaysia', IDE Discussion Paper No. 453, Institute of Developing Economies, Chiba, Japan.

Michida, E., Y. Ueki, and K. Nabeshima (2014), 'Role of supply chains in adopting product related environmental regulations: Case studies of Vietnam', IDE Discussion Paper No. 343, Institute of Developing Economies, Chiba, Japan.

Otsuki, T., E. Michida, K. Nabeshima, and Y. Ueki (2014), 'Estimating the effect of chemical safety standards on firm performance in Malaysia and Vietnam', IDE Discussion Paper No. 455, Institute of Developing Economies, Chiba, Japan.

Palmer, K., W. E. Oates, and P. R. Portney (1995), ‘Tightening environmental standards: The benefit-cost or the no-cost paradigm?' Journal of Economic Perspectives 9(4): 119-132.

Porter, M. and C. van der Linde (1995), 'Toward a new conception of the environment competitiveness relationship', Journal of Economic Perspective 9(4): 97-118.

Rexhäuser, S. and C. Rammer (2014), 'Environmental Innovations and Firm Profitability: Unmasking the Porter Hypothesis', Environmental and Resource Economics 57(1): 145-167. 
Rubashkina, Y., M. Galeotti, and E. Verdolini (2015), 'Environmental regulation and competitiveness: Empirical evidence on the Porter Hypothesis from European manufacturing sectors', Energy Policy 83: 288-300.

Topalova, P. and A. Khandelwal (2011), 'Trade liberalization and firm productivity: The case of India', Review of Economics and Statistics 93(3): 995-1009.

Un, C. A. and A. Cuervo-Cazurra (2008), 'Do subsidiaries of foreign MNEs invest more in R\&D than domestic firms?' Research Policy 37(10): 1812-1828.

Yang, C-H. and Y. H. Chen (2012), 'R\&D, productivity, and exports: Plant-level evidence from Indonesia', Economic Modelling 29: 208-216.

Yang, C-H., Y. H. Tseng, and C.P. Chen (2012), 'Environmental regulations, induced R\&D, and productivity: Evidence from Taiwan's manufacturing industries', Resource and Energy Economics 34: 514-532. 
Table 1. Summary Statistics of Samples

\begin{tabular}{|c|c|c|c|c|}
\hline & Malaysia & Vietman & RoHS & REACH \\
\hline Food products & 34 & 99 & & \\
\hline Beverages & 6 & 9 & & \\
\hline Tobacco products & 0 & 6 & & \\
\hline Textiles & 8 & 50 & ○ & o \\
\hline Wearing apparel & 10 & 270 & o & o \\
\hline Leather and related products & 0 & 42 & $\circ$ & ○ \\
\hline Wood and products of wood and cork, except furniture & 5 & 128 & o & o \\
\hline Paper and paper products & 10 & 7 & o & o \\
\hline Printing and reproduction of recorded media & 11 & 7 & ○ & o \\
\hline Coke and refined petroleum products & 1 & 3 & ○ & ० \\
\hline Chemicals and chemical products & 18 & 9 & o & ○ \\
\hline Basic pharmaceutical products and pharmaceutical preparation & 3 & 7 & ○ & o \\
\hline Rubber and plastic products & 50 & 53 & ० & o \\
\hline Other non-metallic mineral products & 1 & 13 & o & o \\
\hline Basic metals & 41 & 9 & ○ & ० \\
\hline Fabricated metal products, except machinery and equipment & 60 & 15 & o & o \\
\hline Computer, electronic, and optical products & 34 & 16 & ० & o \\
\hline Electrical equipment & 15 & 24 & o & ० \\
\hline Machinery equipment & 23 & 14 & ○ & ० \\
\hline Motor veicles, tailers, and semi-tailers & 3 & 7 & & ० \\
\hline Other transport equipment & 6 & 4 & & ○ \\
\hline Furniture & 8 & 31 & o & 0 \\
\hline Other manufacturing & 23 & 127 & ० & $\circ$ \\
\hline Manufacture Firms & 370 & 950 & & \\
\hline Wholesale and retail trade and repair & 0 & 13 & & \\
\hline Others & 0 & 92 & & \\
\hline Total & 370 & 1055 & & \\
\hline
\end{tabular}

Source: Authors' calculations from the survey of IDE-JETRO.

Note: The mark "O" means the industry is RoHS/REACH targeted. 
Table 2. Summary Statistics of Variables

\begin{tabular}{|c|c|c|c|c|c|c|c|c|c|c|c|}
\hline & \multirow[t]{2}{*}{ Definition } & \multicolumn{5}{|c|}{ Malaysia } & \multicolumn{5}{|c|}{ Vietnam } \\
\hline & & Obs & Mean & SD & Min & Max & Obs & Mean & SD & Min & $\operatorname{Max}$ \\
\hline $\ln R D$ & log of $R \& D$ expenditure & 89 & 13.931 & 2.038 & 8.412 & 19.337 & 79 & 12.616 & 2.184 & 6.802 & 17.083 \\
\hline $\ln T F P$ & $\log$ of TFP & 304 & 1.313 & 1.123 & -1.671 & 4.435 & 569 & -0.466 & 1.411 & -7.614 & 4.854 \\
\hline RoHS & $=1$ if the firm meets RoHS & 152 & 0.809 & 0.394 & 0 & 1 & 112 & 0.875 & 0.332 & 0 & 1 \\
\hline REACH & $=1$ if the firm meets REACH & 127 & 0.701 & 0.460 & 0 & 1 & 126 & 0.865 & 0.343 & 0 & 1 \\
\hline $\ln E M P$ & log of \# of employees & 370 & 4.101 & 1.383 & 0.000 & 8.006 & 979 & 4.812 & 2.005 & 0 & 13.82 \\
\hline $\ln C A P I$ & $\log$ of (asset/employee) & 370 & 11.589 & 1.559 & 5.902 & 16.901 & 931 & 10.251 & 1.514 & 4.723 & 16.39 \\
\hline $\ln A S S E T$ & $\log$ of (asset/sale) & 356 & -0.660 & 1.534 & -4.200 & 6.369 & 843 & -0.127 & 1.318 & -4.354 & 5.858 \\
\hline $\begin{array}{l}\text { EXPR } \\
\text { With tr }\end{array}$ & $\begin{array}{l}\text { ratio of export to total sale } \\
\text { reatment on missing values }\end{array}$ & 212 & 54.519 & 33.314 & 0 & 100 & 591 & 79.383 & 29.471 & 0 & 100 \\
\hline $\ln R D$ & $\log$ of $R \& D$ expenditure & 370 & 3.351 & 6.045 & 0 & 19.34 & 1055 & 0.945 & 3.375 & 0 & 17.08 \\
\hline RoHS & $=1$ if the firm meets RoHS & 370 & 0.332 & 0.472 & 0 & 1 & 1055 & 0.093 & 0.29 & 0 & 1 \\
\hline REACH & $=1$ if the firm meets REACH & 370 & 0.241 & 0.428 & 0 & 1 & 1055 & 0.103 & 0.305 & 0 & 1 \\
\hline
\end{tabular}

Source: Authors' calculations from the survey of IDE-JETRO. 
Table 3. Impact of PRERs on R\&D Expenditure

\begin{tabular}{|c|c|c|c|c|c|c|c|c|c|}
\hline & (1) & $\begin{array}{c}(2) \\
\text { RoHS } \\
\end{array}$ & (3) & (4) & $\begin{array}{c}(5) \\
\text { REACH }\end{array}$ & (6) & (7) & $\begin{array}{c}8) \\
\text { RorR }\end{array}$ & (9) \\
\hline RoHS & $\begin{array}{c}0.430 \\
(0.394)\end{array}$ & $\begin{array}{c}0.420 \\
(0.396)\end{array}$ & $\begin{array}{l}-0.242 \\
(0.465)\end{array}$ & & & & & & \\
\hline REACH & & & & $\begin{array}{c}0.954 * * \\
(0.380)\end{array}$ & $\begin{array}{l}1.216^{* *} \\
(0.497)\end{array}$ & $\begin{array}{l}1.034 * * \\
(0.436)\end{array}$ & & & \\
\hline RorR & & & & & & & $\begin{array}{c}0.920^{* *} \\
(0.363)\end{array}$ & $\begin{array}{c}1.196^{* * *} \\
(0.462)\end{array}$ & $\begin{array}{c}0.941 * * * \\
(0.356)\end{array}$ \\
\hline $\ln E M P$ & $\begin{array}{c}0.649 * * * \\
(0.0917)\end{array}$ & $\begin{array}{c}0.644 * * * \\
(0.0902)\end{array}$ & $\begin{array}{c}0.571 * * * \\
(0.0837)\end{array}$ & $\begin{array}{c}0.637 * * * \\
(0.104)\end{array}$ & $\begin{array}{c}0.646^{* * *} \\
(0.111)\end{array}$ & $\begin{array}{c}0.595^{* * *} \\
(0.113)\end{array}$ & $\begin{array}{c}0.590 * * * \\
(0.0965)\end{array}$ & $\begin{array}{c}0.592 * * * \\
(0.100)\end{array}$ & $\begin{array}{c}0.555^{* * *} \\
(0.103)\end{array}$ \\
\hline $\ln C A P I$ & $\begin{array}{c}0.780^{* * * *} \\
(0.133)\end{array}$ & $\begin{array}{c}0.782^{* * *} \\
(0.135)\end{array}$ & $\begin{array}{c}0.765^{* * *} \\
(0.127)\end{array}$ & $\begin{array}{c}0.933 * * * \\
(0.169)\end{array}$ & $\begin{array}{c}0.858^{* * * *} \\
(0.188)\end{array}$ & $\begin{array}{c}0.839 * * * \\
(0.172)\end{array}$ & $\begin{array}{c}0.960^{* * *} \\
(0.156)\end{array}$ & $\begin{array}{c}0.893 * * * \\
(0.172)\end{array}$ & $\begin{array}{c}0.870 * * * \\
(0.162)\end{array}$ \\
\hline $\ln A S S E T$ & $\begin{array}{c}-0.647 * * * \\
(0.117)\end{array}$ & $\begin{array}{c}-0.649 * * * \\
(0.118)\end{array}$ & $\begin{array}{c}-0.700^{* * * *} \\
(0.129)\end{array}$ & $\begin{array}{c}-0.914 * * * \\
(0.167)\end{array}$ & $\begin{array}{c}-0.874 * * * \\
(0.164)\end{array}$ & $\begin{array}{c}-0.877 * * * \\
(0.159)\end{array}$ & $\begin{array}{c}-0.840^{* * *} \\
(0.152)\end{array}$ & $\begin{array}{c}-0.782 * * * \\
(0.161)\end{array}$ & $\begin{array}{c}-0.808 * * * \\
(0.158)\end{array}$ \\
\hline$E X P R$ & $\begin{array}{c}0.0125^{* * *} * \\
(0.00414)\end{array}$ & $\begin{array}{c}0.0126^{* * * *} \\
(0.00411)\end{array}$ & $\begin{array}{c}0.0154 * * * \\
(0.00414)\end{array}$ & $\begin{array}{c}0.00447 \\
(0.00512)\end{array}$ & $\begin{array}{c}0.00441 \\
(0.00557)\end{array}$ & $\begin{array}{c}0.00670 \\
(0.00548)\end{array}$ & $\begin{array}{l}0.0101 * * \\
(0.00442)\end{array}$ & $\begin{array}{l}0.0109 * * \\
(0.00462)\end{array}$ & $\begin{array}{c}0.0121 * * * \\
(0.00458)\end{array}$ \\
\hline Industry FE & $\mathrm{N}$ & Y & Y & $\mathrm{N}$ & Y & Y & $\mathrm{N}$ & Y & $\mathrm{Y}$ \\
\hline Firm FE & $\mathrm{N}$ & $\mathrm{N}$ & Y & $\mathrm{N}$ & $\mathrm{N}$ & Y & $\mathrm{N}$ & $\mathrm{N}$ & $\mathrm{Y}$ \\
\hline Constant & $\begin{array}{l}-0.673 \\
(1.774)\end{array}$ & $\begin{array}{c}-0.642 \\
(1.769)\end{array}$ & $\begin{array}{l}-0.406 \\
(1.472)\end{array}$ & $\begin{array}{l}-2.702 \\
(2.265)\end{array}$ & $\begin{array}{l}-1.167 \\
(2.556)\end{array}$ & $\begin{array}{l}-0.838 \\
(2.300)\end{array}$ & $\begin{array}{l}-2.879 \\
(2.075)\end{array}$ & $\begin{array}{l}-1.397 \\
(2.310)\end{array}$ & $\begin{array}{l}-1.071 \\
(2.127)\end{array}$ \\
\hline Observations & 152 & 152 & 152 & 147 & 147 & 147 & 171 & 171 & 171 \\
\hline
\end{tabular}


Table 4. Impact of PRERs on TFP

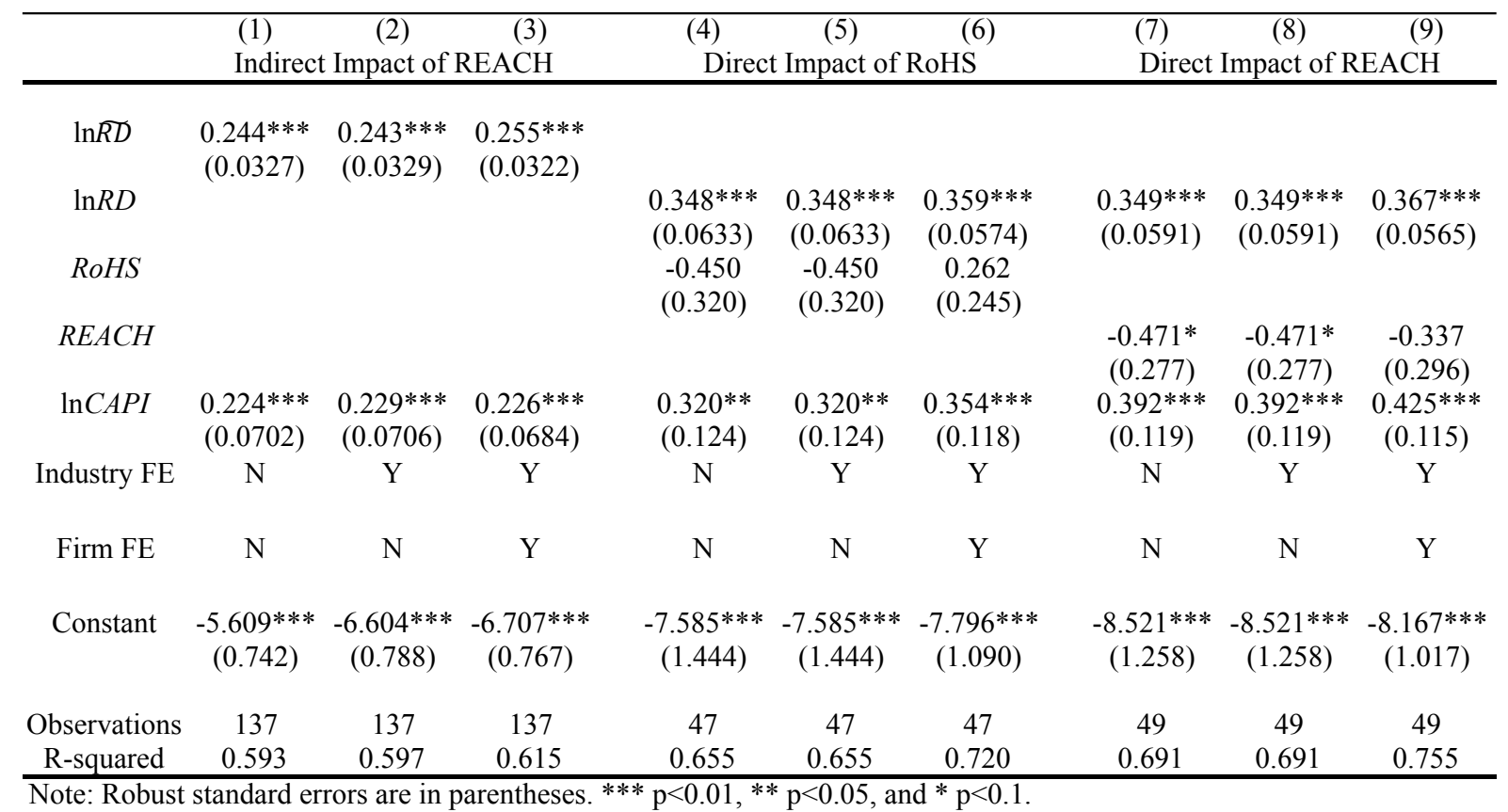


Table 5. Marginal Effects of the Regression with Treatment on Missing Values

\begin{tabular}{|c|c|c|c|c|c|c|}
\hline & (1) & (2) & (3) & (4) & (5) & (6) \\
\hline RoHS & -0.171 & 0.759 & -0.194 & 0.715 & -0.0722 & 0.775 \\
\hline & $(0.491)$ & $(0.896)$ & $(0.490)$ & $(0.890)$ & $(0.500)$ & $(0.890)$ \\
\hline RoHS ${ }^{*}$ Country & & -1.285 & & -1.257 & & -1.181 \\
\hline & & $(1.035)$ & & $(1.031)$ & & $(1.033)$ \\
\hline Industry FE & $\mathrm{N}$ & $\mathrm{N}$ & $\mathrm{Y}$ & $\mathrm{Y}$ & Y & Y \\
\hline Firm FE & $\mathrm{N}$ & $\mathrm{N}$ & $\mathrm{N}$ & $\mathrm{N}$ & Y & $\mathrm{Y}$ \\
\hline Observations & 695 & 695 & 695 & 695 & 695 & 695 \\
\hline & (7) & (8) & (9) & $(10)$ & $(11)$ & $(12)$ \\
\hline$R E A C H$ & $1.157 * *$ & $2.489 * * *$ & $1.129 * *$ & $2.437 * * *$ & $1.180 * * *$ & $2.415 * * *$ \\
\hline & $(0.457)$ & $(0.693)$ & $(0.455)$ & $(0.689)$ & $(0.457)$ & $(0.691)$ \\
\hline REACH*Country & & $-2.150 * *$ & & $-2.114 * *$ & & $-2.014 * *$ \\
\hline & & $(0.868)$ & & $(0.866)$ & & $(0.876)$ \\
\hline Industry FE & $\mathrm{N}$ & $\mathrm{N}$ & $\mathrm{Y}$ & $\mathrm{Y}$ & Y & $\mathrm{Y}$ \\
\hline Firm FE & $\mathrm{N}$ & $\mathrm{N}$ & $\mathrm{N}$ & $\mathrm{N}$ & $\mathrm{Y}$ & $\mathrm{Y}$ \\
\hline Observations & 695 & 695 & 695 & 695 & 695 & 695 \\
\hline
\end{tabular}


Table 6. Input and Output Price Change

\begin{tabular}{|c|c|c|c|c|}
\hline & (1) & (2) & (3) & (4) \\
\hline & \multicolumn{2}{|c|}{ Input Change } & \multicolumn{2}{|c|}{ Price Change } \\
\hline & RoHS & REACH & RoHS & $\mathrm{REACH}$ \\
\hline RoHS & $\begin{array}{c}1.017 * * \\
(0.469)\end{array}$ & & $\begin{array}{l}-0.337 \\
(0.222)\end{array}$ & \\
\hline$R E A C H$ & & $\begin{array}{c}0.188 \\
(0.386)\end{array}$ & & $\begin{array}{r}-0.170 \\
(0.216)\end{array}$ \\
\hline $\ln E M P$ & $\begin{array}{c}0.223 * * \\
(0.105)\end{array}$ & $\begin{array}{c}0.278^{* * *} \\
(0.106)\end{array}$ & $\begin{array}{c}0.0365 \\
(0.0585)\end{array}$ & $\begin{array}{c}0.0301 \\
(0.0598)\end{array}$ \\
\hline Industry FE & Y & Y & $\mathrm{Y}$ & Y \\
\hline Firm FE & $\mathrm{Y}$ & $\mathrm{Y}$ & $\mathrm{Y}$ & $\mathrm{Y}$ \\
\hline Observations & 210 & 199 & 218 & 214 \\
\hline
\end{tabular}

